\title{
Desertización en África
}

\author{
Manuel Soria Pérez
}

Más de una tercera parte de las tierras emergidas del Planeta son extensiones áridas sometidas, con diferentes modalidades e intensidades, a un déficit de agua durante todo el año o de forma estacional.

En el interior de estas zonas (sobre todo en las zonas semiáridas) y en su periferia, el hombre provoca, con sus prácticas de explotación, degradaciones sucesivas que destruyen progresivamente la vegetación y cambian las características de los suelos. A este proyecto de degradación más o menos reversible se le da el nombre de desertificación.

La desertificación es por lo tanto un proceso dinámico de degradación de los ecosistemas y de los suelos, los cuales adquieren en sucesivas etapas una fisonomfa desértica y una forma de funcionar que recuerda a los verdaderos desiertos.

Se está hablando sobre el peligro que corre el mundo con la desforestación de la cuenca del Amazonas, en América del Sur, la mancha verde más extensa de la Tierra; se está poniendo mucho énfasis (y siempre será poco) en denunciar las prácticas de ciertas sociedades consistentes en quemar la selva y en talar árboles, para dejar espacios para siembras más productivas a corto plazo.

Sin embargo, nadie se acordo de Africa hasta que hubo un desastre ecologico por la década de los años setenta en la región del Sur del Sahara, el Sahel, donde miles de vidas humanas se perdían y otras aparecian en los noticiarios y en las televisiones de todo el mundo en un estado de desnutrición irreversible. Y se vieron imágenes de Etiopía y Sudán que nunca se debieron dar y sobre todo en un tiempo donde hay excedentes alimentarios y se sabe todo sobre desertización y además existen toda clase de medios para salvar de la muerte a tantos seres humanos.

Africa fue esquilmada poco a poco desde principios de siglo por las potencias europeas que deberian haber puesto más atención al cuidado de unas tierras vírgenes que tenían por delante un futuro de vida y no de muerte, que es lo que hoy en día se nos avecina. $Y$ también el mundo entero sufrirfa las consecuencias de esta catástrofe que como la de Brasil, la de Indonesia y como la de ciertas regiones de Asia, está cercenando las posibilidades de vida en nuestro Planeta.

Ya se conoce el peligro de la desertización en Europa y en América del Norte. En Espana, en ciertas zonas, es preocupante; por ello, ayudando a Africa nos ayudamos a nosotros mismos.

La desertización es un problema antiguo cuyas causas se han estudiado y 
cuyas soluciones se han dado también. $Y$ se considera que se podía detener este proceso, salvar millones de vidas humanas y acabar con el deterioro de extensas regiones de la Tierra.

La Organización de las Naciones Unidas para la Agricultura y la Alimentación, FAO, estima que en Africa, al sur del Sahara, en la región llamada Sahel existe un potencial irrigable de treinta y cuatro millones de hectáreas, mientras que las tierras que actualmente están regadas cubren sólo cinco millones de hectáreas.

El "Programa para el Medio Ambiente de las Naciones Unidas", con sede en Nairobi, Kenia, ha calculado que en los bordes del Sahara, se está extendiendo el desierto a un ritmo de un millón y medio de hectáreas por afoo. Los seis principales países del Sahel, junto a Sudán y Etiopía están perdiendo terreno cultivable, cuando su población pasa hambre. El aumento de la población del Sahel es de un millón y medio de personas al año; ya no hay alimentos para tantas bocas. Miles de personas de esta región se refugian en los núcleos de población donde puedan alimentarlos, agravando la situación de esos lugares ya de por sí delicados. Ayudas internacionales han llevado alimentos a tantas bocas hambrientas, pero resultan insuficientes. Muchos miles de millones de dólares se han destinado a los parses del Sahel para paliar en lo posible el terrible desastre que supone para las personas y las tierras que no llueva lo suficiente. Pero por el momento el problema subsiste y se puede pensar lógicamente que las ayudas no han sido dirigidas en su correcta dirección.

En 1974, la Asamblea General de la ONU hizo un llamamiento para organizar una conferencia internacional sobre la materia y convoc 6 la "Conferencia de las Naciones Unidas sobre Desertización" (UNCOD), que se celebró en Nairobi en 1977 y presentó un "Plan de Acción para Combatir la Desertización". La ONU también estableció la Oficina Sudano-Saheliana para coordinar la ayuda destinada a los parses del Sahel.

En 1973, Mall, Mauritania, Niger, Senegal y Alto Volta (Burkina-Faso) fundaron l CILSS, una Comisión internacional para luchar contra la sequia en el Sahel, a fin de representar los intereses de la región ante los donantes. Chad se hizo rápidamente miembro del CILSS, y Gambia y Cabo Verde se unieron más tarde. La ayuda en forma de dinero y alimentos, entro a raudales: entre 1975 y 1980 los donantes suministraron a los miembros del CILSS una ayuda valorada en 7.500 millones de dolares. En este periodo, la ayuda en el Sahel ascendió de 23 a 40 dólares per cápita. En 1974 el CILSS declaró que sus objetivos eran mitigar las consecuencias de futuras crisis, hacer a la región autosuficiente en alimentos y acelerar el desarrollo económico y social. Desgraciadamente, desde la UNCOD se ha hecho pocos progresos para detener la desertización. El Plan de Acción para combatir la desertización contenía algunas propuestas útiles, pero pocas han sido llevadas a cabo. A pesar de que la Oficina Sudano-Saheliana recibió 162 millones de dolares en concepto de ayuda para los paises del Sahel, solo se ha empleado un $8 \%$ en actividades relativas a prevenir 
la desertización.

Hacia 1980 la ayuda a los países del CILSS era de 1.500 millones de dolares anuales, pero se gastó un $24 \%$ en mejorar la agricultura y la silvicultura. En 1.975 solo se gastó en la reforestación un diminuto $0,35 \%$ de toda la ayuda prestada a la zona. Incluso en 1980 , el porcentaje era de un $24 \%$. Casi la décima parte de toda la ayuda se gastó en irrigación. Pero, aunque esto supone el cultivo de alrededor de 5.000 nuevas hectáreas de regadío, cada año en el Sahel una cantidad similar se pierde por anegación, salinización o alcalinización.

Como se ve la ayuda ha sido importante pero los resultados no son satiactorios y entonces nos preguntamos ¿que puede hacerse?

Lo primero que se nos ocurre es que a pesar de los resultados no muy concluyentes, se debe seguir en la lucha por detener la desertización, pues hay técnicas disponibles que podrian ayudar a detener y estabilizar zonas y que sus propios moradores se autoabastecieran y una de las previsiones que se apuntan para tal fin es evitar el paso de animales y controlar el paso de rebaños y, sobre todo, controlar el número de cabezas de ganado para que no causen tanto daño al suelo.

También cuidar la roturación de tierras con especies apropiadas. El Plan de Acción de la UNCOD contenra recomendaciones especificas, las más importantes de ellas eran: que cada nación afectada podra presentar su propio plan para combatir el problema; que se crearian centros regionales para investigar y demostrar, por ejemplo, qué puede hacerse para mejorar los cultivos de secano, las técnicas de irrigación, la cría del ganado y los niveles de reforestación.

En realidad poco se ha prosperado, pocos gobiernos han puesto en práctica algún plan y los que se han iniciado han quedado sin desarrollar. Se aducen muchas razones, siendo la principal la falta de dinero. Así en un estudio de la ONU se calculo que para detener la desertización en el Sahel para el af́o 2.000 serfan necesarios 4,5 millones de dólares al anfo. Aunque esta cifra parezca elevada, recordemos que según otro estudio de la ONU, la pérdida anual en la producción agrícola a causa de la desertización ascendfa a 26.000 millones de dólares.

Debemos de hacer una serie de reflexiones basadas en hechos contrastados para comprender bien el problema que nos avecina si no podemos coto al hecho de la desertización.

Estos hechos contrastados que voy a citar están entresacados de publicaciones y comunicaciones de reconocida solvencia internacional, como pueden ser los programas de las Naciones Unidas para el Medio Ambiente; la Union Internacional para la Conservación de la Naturaleza y los Recursos Naturales UICN: Informes del Banco Mundial; la publicación Ecologia 2.000, de Sir Edmund Hillary; Nicole Petit-Marie, investigadora del Laboratorio de Geologia del Cuaternario CNRS; diversos informes de la FAO, Organización de las NN. UU. para la Agricultura y la Alimentación, etc. 
Voy a comentar en primer lugar una fotografía tomada por satélite del Desierto de Sinar en que se ve la frontera de Israel y Egipto. En la parte israelr aparece alguna vegetación, pero la parte egipcia aparece seca. Y esto sólo con la presencia de rebaños incontrolados de cabras en la parte egipcia. En territorio israelf sólo el abandono; la tierra puede recuperarse casi sin ayuda del hombre.

Se dice que los países adelantados están transformando sus mejores tierras en pavimento, mientras que los países pobres las están transformando en desiertos.

La curva de Niger, desde Gao hasta Tombuctú, continuando por el Oeste hacia Bamako y por el Sur hacia Niger y Burkina Faso, es hoy en día un erial. $Y$ all no falta agua, pero el descuido humano ha hecho desiertos donde existra una gran masa forestal y por tanto vida.

La desertización de Africa no ayudará precisamente a los demás continentes a mantener las constantes climáticas normales. La regresión de las zonas verdes africanas será negativa en el sentido ecologico mundial. Las tierras del Sur y Norte de la cuenca mediterránea se ven afectadas por la desertización. El clima del Sahel está regido fundamentalmente, entre otras cosas, por la circulación atmosférica a escala global, pero hay factores locales que explican la gravedad de lo que acontece hoy en esta región. Ya en época del colonialismo se hizo un gasto excesivo de madera, se talaron los bosques a orillas del Niger. Se hizo y se sigue haciendo un pastoreo exagerado y se han introducido prácticas agricolas que no favorecen a las tierras.

A menos que todas las naciones actúen juntas para cambiar estas tendencias (de desertización), las presiones implacables sobre una base limitada de recursos - nuestro frágil pequeño planeta - acabarán por empobrecer la calidad de vida de todos sus habitantes para fines de siglo $\mathrm{XX}$, incluso aunque se de una mayor producción material.

Como hemos dicho, un tercio de la superficie de la Tierra es árida o semiárida. A pesar de la escasa precipitación, las tierras áridas pueden ser asombrosamente productivas, y pastores y agricultores adiestrados podrian arreglárselas para vivir en los frágiles ambientes desérticos sin explotarlos excesivamente si su número se mantiene en equilibrio con lo que la tierra puede soportar. Las tierras áridas son el hogar de unos setecientos millones de personas en todo el mundo. Ochenta y un millones viven en el Sahel y las regiones del Sudán.

Con el aumento incesante de la población, la necesidad de aumentar la producción supuso el acortamiento e, incluso la supresión del periodo de barbecho en favor de un cultivo intensivo permanente, al que se affadía el uso de la tierra, como pastizal. Se perdió as la flexibilidad de los sistemas más tradicionales e, invitablemente la tierra, sobreexplotada, volvióse cada vez mas esteril.

Estamos hablando de la desertización en Africa y Ceuta y Melilla son territorios espaffoles en este Continente y deberian dar ejemplo de cuidadosa aten- 
ción y respeto al Medio que nos rodea, pero ¿son verdaderamente ejemplos?

La contestación es rápida y tajante, no. Estamos despilfarrando lo que tenemos en nuestro entorno y nuestras posibilidades. Las dos ciudades están muy descuidadas en el aspecto urbanístico, en el medio ambiental están aun peor. Polucionamos las aguas que nos rodean, tiramos al mar sustancias contaminantes sin preocupación. Los puertos de las dos ciudades se han hecho inhabitables para las especies marinas que antes vivian en unas aguas cristalinas.

El aire lo enrarecemos, quemamos nuestras basuras, en vez de reciclarlas y no ponemos coto a nuestra propia incapacidad de hacer de estos pequeños territorios lugares ideales para vivir ¿hasta dónde llegaremos?

Los nifos no tienen donde jugar, paseos, parques y jardines se cubren de alquitrán y cemento. Los pájaros carecen de posibilidades de vida. Hace algunos años el cielo de nuestras costas lo alegraban miles de gaviotas que encontraban acomodo y alimento. Hoy en día toda clase de pájaros han tenido que emigrar a zonas más límpias. Los parques y jardines se degradan. En Melilla en el parque de la Ciudad se celebran toda clase de Ferias, destrozando especies arboreas con cerca de un siglo de existencia.

Dos ciudades que apenas sobrepasan las tres mil hectáreas, que deberfan ser escaparates maravillosos de una potencia europea que va a celebrar con fasto y lujos desproporcionados el descubrimiento de un nuevo mundo, que solo demuestra la pobreza intelectual de quienes olvidan la realidad para dedicarse a festejos y jaranas.

Dos ciudades que deberfan ser laboratorios de experimentación del entomo africano, con el estudio de las aguas de mar, de los acuiferos, las aguas de lluvia y de su tratamiento y mejora para los regadios y el consumo humano. Con el estudio de las energf́as eólicas y solares, estudios sobre el medio ambiente, de los cultivos de aclimatación. El aprovechamiento de las basuras, etc.

Nuestras dos ciudades africanas, con una población total de menos de ciento cincuenta mil habitantes y lugar de paso de una gran emigración humana, son hoy un mal ejemplo de 10 que podían ser dos ciudades modernas puestas al servicio de nuestro tiempo y de nuestra sociedad. Y lo más contradictorio de todo es que medios económicos no faltan. Pero los presupuestos millonarios de nuestras dos ciudades se malgastan y la calidad de vida está muy por debajo de lo que se deberfan conseguir a juzgar con las disponibilidades con que se cuenta. Hay restricciones de agua, pocas zonas verdes y arboladas y no se hace nada para mejorar la situación, no hay ninguna planta potabilizadora o desalinizadora ni se reconvierten las basuras, sino todo lo contrario, sirven para polucionar aún más.

Desde una perspectiva más progresista podria hacerse desde Melilla y Ceuta algo concreto, desde posturas ecologistas, por mejorar, primero nuestro hábitat que está bastante deteriorado y más adelante aportar a nuestro Continente técnicas más avanzadas sobre aspectos medio ambientales, cómo combatir la desertización, utilizacion de métodos de cultivo y las diversas prácticas de riego, 
etc. Se podria investigar sobre todo lo anteriormente citado y contribuir con nuestras posibilidades como nación adelantada en el campo de las ciencias a que este Continente sea más habitable. Tenemos que justificar nuestra presencia en Africa. 